\title{
Airways in Apartment Buildings as a Method of Thermal Control
}

\author{
Anna Suslova ${ }^{1,}{ }^{*}$, Michail Petrichenko ${ }^{1}$ and Aleksandr Sivokhin ${ }^{1}$ \\ ${ }^{1}$ St. Petersburg State Polytechnical University, 19525 Polytecknycheskaya str. 29, St. Petersburg, \\ Russia.
}

\begin{abstract}
In general, the majority of modern apartment buildings are rather high. Altitude of such structures attains 50 meters. It is clear that for such high structures every extra meter of elevation costs a lot. For this reason, architects are trying to avoid adding attics above the last floor of the buildings. However, attic is not only an architectural element. It is an important part of the thermal control process of the entire building, especially of the apartments located on the last floor. In this article, construction of airways under the roof is suggested and discussed in detail. Airway acts as an attic, but has a significantly lower construction cost due to the lower height. Application of this technology allows providing comfortable microclimate on the living quarters in an economical way.
\end{abstract}

\section{Introduction}

Construction of traditional attic means presence of a big amount of free space for communications under the roof. Airway acts as a garret in temperature control field due to the working-section equality. Whole area of the attic functions like a heat insulator because of the air inside. But by imposing motion to this air and reducing its temperature, similar thermal effect can be achieved with garret of lower height.

The idea of not using attic is not new. Since the beginning of 20th century a lot of new buildings avoid additional construction elements like garrets. It gives an economical effect but causes some problems, such as icicle formation on the edges of housetop, high moisture of the last floor apartments, strong dependence of the temperature inside the flats from weather conditions. To avoid these problems, airway can be applicated. Air moving under the housetop makes the lowest layer of the roof construction cooler. It prevents snow from melting on the roof during the winter. At the same time, temperature of this air is higher than outside, therefore providing more comfortable temperature in the dwelling. During the summer, airway prevents excessive heating of the building.

There are some articles about attic ventilation from all around the world [1-8, 14-17, 2629], particularly from Russia [9-13, 18-21, 30]. They are made not only by professionals, but also by ordinary private house owners. Comprehensive research work was performed by Mark Graham $[14,15]$. HVAC-systems and the branches of knowledge connected with it are widely explored. Topics are various: from preventing ice damming by different

* Corresponding author: suslovanya@mail.ru 
measures [12, 18, 20, 31-32], to economic effects of modern materials and technologies usage [21]. The main problem of all those researches is that they do not take into account the altitude of the building. For high apartment buildings speed of the wind on the top of them is big enough to use it without any fans. Wind speed influence on temperature inside the airway is considered in this paper.

\section{Theory or experimental methods}

The main goal of this article is to estimate the optimal cross section of an airway and evaluate its efficiency. The criteria the conclusion is based on is the temperature under the roof and over the covering slab of the last floor. Temperature should be high enough to provide the sufficient amount of heat to the last floor and low enough to exclude the icicle formation on the roof. Optimal temperature is calculated according to the first law of thermodynamics. Based on this temperature, the necessary cross section can be estimated by using boundary problem solutions.

\section{Research description}

First of all, optimal height of an attic should be estimated. It can be made, according to the governmental standard in Saint-Petersburg [22]. The medium temperature outside during the winter is $-4.6^{\circ} \mathrm{C}$. Temperature in bedrooms and living rooms is $20^{\circ} \mathrm{C}$, according to sanitary regulations [23]. Temperature inside the roof space should be at least $-1.6^{\circ} \mathrm{C}$ to prevent icicle formation [24]. Using the first law of thermodynamics, the heat balance of the garret can be written:

$$
0=Q_{\text {slab }}-Q_{\text {walls }}-Q_{\text {roof }}
$$

According to the Newton-Rixman law:

$$
q=\alpha \cdot \Delta T
$$

Where $\mathrm{q}$ - heat-flow rate, $\alpha$ - heat-transfer coefficient, $\Delta \mathrm{T}$ - temperature difference. Heat flow for all the filler structures is:

$$
\left\{\begin{array}{c}
q=\alpha_{h} \cdot\left(T_{h}-T_{0}\right) \\
q=\frac{\lambda \cdot\left(T_{0}-T_{1}\right)}{\delta} \\
q=\alpha_{c} \cdot\left(T_{1}-T_{c}\right)
\end{array}\right.
$$

Where $\alpha_{\mathrm{h}}$ and $\alpha_{\mathrm{c}}$ are heat-transfer coefficients of the material inside and outside the building, $\mathrm{T}_{\mathrm{h}}$-inside temperature $\mathrm{T}_{\mathrm{h}}=20^{\circ} \mathrm{C}, \mathrm{T}_{\mathrm{c}}$-outside temperature $\mathrm{T}_{\mathrm{c}}=-4.6^{\circ} \mathrm{C}, \mathrm{T}_{0}$ and $\mathrm{T}_{1}$ are the walls surface temperatures, $\lambda$ is a thermal conductivity coefficient, $\delta$ is a thickness of the walling. Solving given system, the following results have been obtained:

$$
q=\frac{T_{h}-T_{c}}{\frac{1}{\alpha_{h}}+\frac{\delta}{\lambda}+\frac{1}{\alpha_{c}}} ;
$$

Estimate the amount of heat per time by heat-flow rate: 


$$
Q=q \cdot A
$$

Where $\mathrm{A}$ is an area of the surface.

$$
Q=\frac{T_{h}-T_{c}}{\frac{1}{\alpha_{h}}+\frac{\delta}{\lambda}+\frac{1}{\alpha_{c}}} \cdot A
$$

Similar equations for all the filling structures are written below:

$$
\begin{gathered}
Q_{\text {wall }}=2 \frac{T_{\text {attic }}-T_{c}}{\frac{1}{\alpha_{h}}+\frac{\delta_{\text {wall }}}{\lambda_{\text {wall }}}+\frac{1}{\alpha_{c}}} \cdot l \cdot h ; \\
Q_{\text {slab }}=\frac{T_{h}-T_{\text {attic }}}{\frac{1}{\alpha_{h}}+\frac{\delta_{1 \text { slab }}}{\lambda_{1 \text { slab }}}+\frac{\delta_{\text {2slab }}}{\lambda_{2 \text { slab }}}+\frac{1}{\alpha_{c}}} \cdot l \cdot a ; \\
Q_{\text {roof }}=\frac{T_{\text {attic }}-T_{c}}{\frac{1}{\alpha_{h}}+\frac{\delta_{\text {roof }}}{\lambda_{\text {roof }}}+\frac{1}{\alpha_{c}}} \cdot l \cdot a .
\end{gathered}
$$

Put equations Eq. 7 - Eq.9 into Eq.1:

$$
\frac{T_{h}-T_{\text {attic }}}{\frac{1}{\alpha_{h}}+\frac{\delta_{1 \text { slab }}}{\lambda_{1 \text { slab }}}+\frac{\delta_{2 \text { slab }}}{\lambda_{2 \text { slab }}}+\frac{1}{\alpha_{c}}} \cdot l \cdot a=\frac{T_{\text {attic }}-T_{c}}{\frac{1}{\alpha_{h}}+\frac{\delta_{\text {roof }}}{\lambda_{\text {roof }}}+\frac{1}{\alpha_{c}}} \cdot l \cdot a+2 \frac{T_{\text {attic }}-T_{c}}{\frac{1}{\alpha_{h}}+\frac{\delta_{\text {wall }}}{\lambda_{\text {wall }}}+\frac{1}{\alpha_{c}}} \cdot l \cdot h .
$$

All the parameters of the walls, the slab and the roof are supposed to be typical for residential buildings: $\alpha_{\mathrm{h}}=23 \frac{\mathrm{W}}{\mathrm{m}^{2} \cdot \mathrm{K}}, \alpha_{\mathrm{c}}=8.7 \frac{\mathrm{W}}{\mathrm{m}^{2} \cdot \mathrm{K}}, \delta_{1 \mathrm{slab}}=\delta_{\text {walls }}=0.2 \mathrm{~m}$; the walls and the slab are made from reinforced concrete: $\lambda_{\text {walls }}=\lambda_{1 \mathrm{slab}}=2.04 \frac{\mathrm{W}}{\mathrm{m}^{2} \cdot \mathrm{K}}$, the slab is also winterized by a mineral wool insulation: $\delta_{2 \text { slab }}=0.15 \mathrm{~m}, \lambda_{2 \text { slab }}=0.048 \frac{\mathrm{w}}{\mathrm{m}^{2} \cdot \mathrm{K}}$, the roof itself is made from the mineral wool insulation: $\delta_{\text {roof }}=0.15 \mathrm{~m}, \lambda_{\text {roof }}=0.048 \frac{\mathrm{w}}{\mathrm{m}^{2} \cdot \mathrm{K}}$. Only meaning layers are taken into account. The attic section dimensions are: $1=20 \mathrm{~m}, \mathrm{a}=10 \mathrm{~m}$. According to those data, $\mathrm{h}$ can be determined.

After the calculations, it is achieved that $h=2.1 \mathrm{~m}$ is enough to prevent the icicle formation on the housetop of a typical building. It is an ordinary height of the attic, but it seems that to achieve this result it is necessary to use a large amount of heater both on the roof and the slab. Another option is to provide a natural ventilation for the under-roof space. It can be achieved by using the airways.

Mean wind speed on the top of the building is governed by governmental regulations. Regulatory wind speed, according to geographic position, is $27 \mathrm{~m} / \mathrm{sec}$. Coefficient of correction is equal to 1 because of the type of the region and the height of the building.

Pressure losses take place on entrance, exit and along the airway.

$$
\begin{gathered}
\Delta P=\Delta P_{\text {in }}+\Delta P_{\text {out }}+\Delta P_{\text {fr }} ; \\
\Delta P=\xi_{\text {in }} \cdot \rho \cdot \frac{v_{\infty}^{2}}{2}+\xi_{\text {out }} \cdot \rho \cdot \frac{v_{\text {in }}^{2}}{2}+\lambda \frac{L}{d} \cdot \rho \cdot \frac{v_{\text {in }}^{2}}{2}=\rho \cdot \frac{\left(v_{\infty}-v_{\text {in }}\right)^{2}}{2}
\end{gathered}
$$




$$
\xi_{\text {in }}=\frac{1-\frac{S_{\text {in }}}{S_{\text {out }}}}{2}, \xi_{\text {out }}=\left(1-\frac{S_{\text {in }}}{S_{\text {out }}}\right)^{2}
$$

Since $\frac{s_{\text {in }}}{S_{\text {out }}} \longrightarrow 0$, then $\xi_{\text {in }}=0.5$ and $\xi_{\text {out }}=1$.

$$
\begin{gathered}
\lambda=0.11 \cdot\left(\Delta_{e q}\right)^{0.25}=0.11 \cdot\left(\frac{k \cdot P}{4 \cdot A}\right)^{0.25}=0.11 \cdot\left(\frac{0.002 \cdot 2}{4 \cdot 0.3 \cdot 0.3}\right)^{0.25}=0.036 \\
P_{1}=\Delta P \\
\frac{27^{2}}{2}=\frac{1}{2} \cdot \frac{27^{2}}{2}+\frac{v_{i n}^{2}}{2}+0.036 \cdot \frac{20}{0.5} \cdot \frac{v_{\text {in }}^{2}}{2} \\
\mathrm{v}_{\text {in }}=12.2 \mathrm{~m} / \mathrm{sec} .
\end{gathered}
$$

As soon as wind speed inside the airway is known, it is possible to determinate the cooling effect of an air circulation under the roof.

Energy conservation law, according to the heat power looks like:

$$
\rho \cdot v_{i n} \cdot A \cdot c_{p} \cdot d T=\alpha \cdot\left(T_{h}-T\right) \cdot d A,
$$

On the Fig. 1 cross section of the attic is shown. Calculations are made on the plate along the wind direction under the housetop. It is supposed that parameters of the roof space are constant in width, so the plane problem can be estimated.

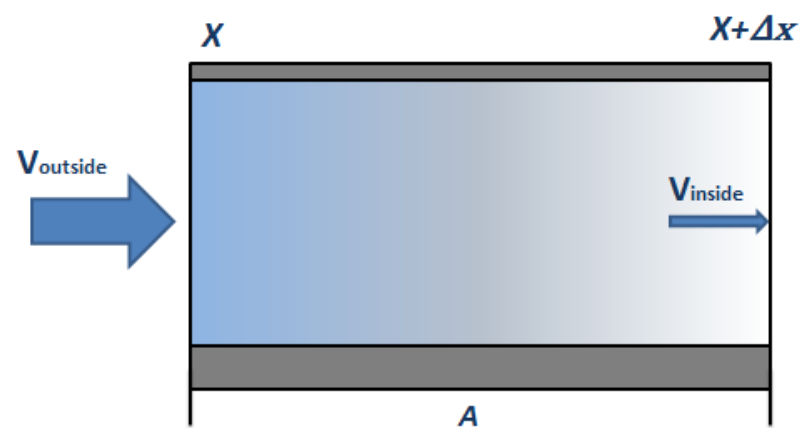

Fig. 1. Attic cross section.

Where $\mathrm{A}$ is the cross section of an attic, $\mathrm{c}_{\mathrm{p}}$ is the transfer characteristic.

$$
d A_{w}=\chi \cdot d x
$$

Where $\chi$ is the coordinate increment in horizontal surface.

$$
\begin{gathered}
\rho \cdot v_{\text {in }} \cdot A \cdot c_{p} \cdot d T=\alpha \cdot\left(T_{h}-T\right) \cdot \chi \cdot d x \\
\frac{d T}{d x}=\frac{\alpha \cdot \chi}{\rho \cdot v_{\text {in }} \cdot c_{p}} \cdot\left(T_{h}-T\right) .
\end{gathered}
$$


Add new quantities: Stanton number and hydraulic radius.

$$
S t=\frac{\alpha}{\rho \cdot v_{i n} \cdot c_{p}} \text { and } R g=\frac{A}{\chi} \text {. }
$$

Put them into the original equation Eq.1:

$$
\frac{d T}{d x}=S t \cdot \frac{\left(T_{h}-T\right)}{R_{g}} ;
$$

Numerical value of them can be estimated:

$$
\begin{gathered}
R_{g}=\frac{h^{2}}{4 \cdot h}=\frac{h}{4}=\frac{0.3}{4}=7.5 \cdot 10^{-2}, \\
S t=\frac{\alpha}{\rho \cdot c_{p} \cdot v_{\text {in }}}=\frac{15.85}{1,293 \cdot 1000 \cdot 12.2}=1 \cdot 10^{-3} .
\end{gathered}
$$

Make the original equation suitable for integration:

$$
\frac{d T}{\left(T_{h}-T\right)}=\frac{S t}{R_{g}} \cdot d x .
$$

Integrate Eq.20 all along the airway:

If $x=0$, then:

$$
-\ln \left(T_{h}-T\right)=\frac{S t}{R_{g}} \cdot x+c ;
$$

$$
\begin{gathered}
-\ln \left(T_{h}-T_{c}\right)=\mathrm{c} \\
\ln \left(T_{h}-T\right)=\ln \left(T_{h}-T_{c}\right)-\frac{S t}{R_{g}} \cdot x .
\end{gathered}
$$

Exponentiate the equation to segregate the decision variable.

$$
\begin{gathered}
T_{h}-T=e^{\frac{S t}{R_{g}} \cdot x-\ln \left(T_{h}-T_{C}\right)} \\
T=20+2.73^{\frac{1 \cdot 10^{-3}}{7.5 \cdot 10^{-2}} \cdot 10-\ln (20+4.6)}=-1.53^{\circ} \mathrm{C} .
\end{gathered}
$$

The estimated temperature under the roof is $-1.53^{\circ} \mathrm{C}$. It means that the icicle formation on the housetop will be prevented.

\section{Results}

Calculations show that the effect from the airway with the cross section $0.3 \times 0.3$ meter is equal to effect of the attic construction with height of 2.1 meter. It is clear that the cost of airway is less than the cost of attic. Saving time and finances during the construction phase is the foreground task for every building project. The airways are easy-making and their 
effect is proved. It makes the application of such kind of construction optimal. Only rectangular attic has been considered. According to other researches, it is possible to produce calculations for all types of roof. In [3] triangular roof is considered and air behavior within the roof is described. Combination with other methods of energy-saving can improve the effect from suggested measures. Some of them are offered in [24]. Generally, the result is highly corresponded with other researches data. Close result was achieved by W. Tobiasson, J. Buska, A. Greatorex [9]. They came to conclusion that icings can be avoided by maintaining an attic temperature of $-1{ }^{\circ} \mathrm{C}$ when the outside temperature is $-5.5^{\circ} \mathrm{C}$.

\section{Conclusions}

The present article has shown the possibility of airway application as a method to prevent the icicle formation on the roof of the apartment buildings during the winter. Evidently, that only the most general case has been considered. For every particular building the calculations should be performed independently.

There are a few factors which significantly increase the overall value of the described method. First of all, implementation of airways can potentially bring tangible monetary benefits due to the fact that this technology is much cheaper than attic construction. Additionally, airways are much easier to plan, design and implement than adding fans and other ventilation systems to a particular building. Finally, airways can be designed, measured and integrated into most of the buildings. Notably, considering the relatively low cost of airways and the overall simplicity of their design and integration, the method described in this article can potentially be found beneficial by construction industry workers.

\section{References}

1. S.C. Saha, J.C. Patterson, C. Lei, International Journal Of Thermal Sciences, 49, 1899-1910 (2010)

2. I. Suwan,S.C. Saha, J.C. Pattersonb, C. Leib, Energy and Buildings, 42, 1192-1204 (2010)

3. S.C. Saha, Energy and Buildings, 43, 695-703 (2011)

4. E.F. Kent, Mechanics Research Communications, 36, 497-508 (2009)

5. T. Basaka, S. Royb, S.K. Babub, A.R. Balakrishnana, International Journal of Heat and Mass Transfer, 51, 4496-4505 (2008)

6. El H. Ridouanea, A. Campob, M. Hasnaouia, International Journal of Heat and Fluid Flow, 27, 476-489 (2006).

7. V.A. Akinsete T.A. Coleman, International Journal of Heat and Mass Transfer, 25, 991-998 (1982)

8. A.D. Suslova, A.D. Sivokhin, Construction of Unique Buildings and Structures, 5, 5464 (2014)

9. W. Tobiasson, J. Buska, A. Greatorex, AVOK: ventilation, heating, air conditioning, heating and Building Thermal Physics, 3, 20-25 (2011)

10. N.I. Shamrikov, V.A. Volnukhin, T.N. Makarova, Gable Roof With Unheated Attic, (R.F. Patent 2263749, 2005)

11. O.A. Sizenko, A.P. Prokhorenko, Stroitel'stvo I Arkhitektura, 4, 46-51 (2009)

12. I.I. Staroverova, Thermal Conditions Of Warm Attics And Adjacent Spaces In Modern Residential High-Rise Buildings In The Cold Season (On The Example Of Construction In Moscow) (Dissertation 1984) 
13. M. Graham, National Roofing Contractors Assn., 7, 1-12 (2015)

14. M.Graham, National Roofing Contractors Assn., 11, 1-12 (2012)

15. J. Straube, Building Science Press. Building Science Digest, 135, 23-28 (2006)

16. P.V. Nielsen, Displacement Ventilation: Theory and Design (Denmark: Aalborg University, 1993)

17. M.R. Petrichenko, V.N. Bukhartsev, Extreme Problems Of Filtration Stream (Palmarium Academic Publishing, 2012)

18. M.R. Petrichenko, Nauchno-Tekhnicheskiye Vedomosti SPBGPU ,1, 108-112 (2012)

19. V.I. Lipko, Magazine of Polotsk State University, B Series : Industry, Applied Science, 9, 40-45 (2006)

20. V.S. Belyaev, V.F. Tikhonova, Residential Buildings Construction, 3, 34-45 (2014)

21. SNiP (Construction Rules and Regulations) № 41-01-2003. Otopleniye, ventilyatsiya i konditsionirovaniye.

22. GOST (Russian National Standard) № 30494-96 Zdaniya zhilyye i obshchestvennyye. Parametry mikroklimata v pomeshchenii

23. D.R. Miftakhova, D.V. Nemova, Construction of Unique Buildings and Structures, 43, 34-45 (2016)

24. A.S. Gorshkov, D.V. Nemova, N.I. Vatin, Construction of Unique Buildings and Structures, 12, 2458 - 2463 (2013)

25. N. Harmati, R. Folić, Z. Magyar, J. Dražić, N. Kurtović-Folić, Thermal Science (Nuclear Institute Vinča, Belgrade, 2015)

26. N. Harmati, Z. Magyar, Energy Procedia, 78, 2458 - 2463 (2015)

27. N. Harmati, Ž. Jakšić, N. Vatin, Procedia Engineering, 117, 791 - 799 (2015)

28. N. Harmati, R. Folić, Z. Magyar, Thermal Science, 19, 865-880 (2015)

29. V. Pukhkal, A. Bieliatynskyi, V. Murgul, Journal of Applied Engineering Science, 14, $93-101$ (2016)

30. V. Okrepilov, Ivanova, G., Standarty i Kachestvo, 12, 62-68 (2004)

31. V. Okrepilov, Standarty i Kachestvo, 3, 94-96 (2003)

32. V. Okrepilov, Standarty i Kachestvo, 10, 52-55 (2015) 